Electronic Supplementary Material (ESI) for RSC Advances.

This journal is @ The Royal Society of Chemistry 2016

\title{
Monovalent cation selective crown ether containing poly(arylene ether ketone/SPEEK blend membranes
}

Sinem Tas, ${ }^{\text {a Bram Zoetebier, }}$ ' Mark A. Hempenius, ${ }^{\mathrm{b}}$ G. Julius Vancso, ${ }^{\mathrm{b}}$ Kitty Nijmeijer ${ }^{{ }^{*}}$

a Membrane Science \& Technology, MESA ${ }^{+}$Institute for Nanotechnology, University of Twente, P.O. Box 217, 7500 AE Enschede, the Netherlands

b Department of Materials Science and Technology of Polymers, MESA ${ }^{+}$Institute for Nanotechnology, University of Twente, P.O. Box 217, 7500 AE Enschede, the Netherlands

Corresponding author:

Kitty Nijmeijer

E-mail: d.c.nijmeijer@utwente.nl

Tel: (+31) (0) 534894185 


\section{Polymer molar mass characteristics}

Molar masses of PAEK and CPAEK were determined using a Shimadzu GPC LC-20AD equipped with a Shodex LF-801 column and a refractive index detector, using NMP-containing $0.5 \mathrm{mM} \mathrm{LiBr}$ as the eluent. GPC measurements for SPEEK were carried out in NMP-containing $5 \mathrm{mM} \mathrm{LiBr}$, using PSS GRAM analytical $30 \AA$ and $1000 \AA$ GPC columns and a dual detection system consisting of a differential refractometer (Waters model 410) and a differential viscometer (Viscotek model H502). Molar masses were determined relative to narrow polystyrene standards. All sample solutions were prepared at a concentration of $1 \mathrm{mg} / \mathrm{mL}$ and filtered through a $0.45 \mu \mathrm{m}$ PTFE filter prior to a GPC run. The number average molecular weight $\left(\mathrm{M}_{n}\right)$ and the polydispersity index (PDI) of the polymers are shown in the table below.

Table S1. Number average molar mass $\left(\mathrm{M}_{n}\right)$ and polydispersity index (PDI) of the polymers.

\begin{tabular}{|c|c|c|}
\hline Polymer & $\mathrm{M}_{\mathrm{n}}(\mathrm{g} / \mathrm{mol})$ & PDI \\
\hline PAEK & 16000 & 1.6 \\
\hline CPAEK & 18000 & 1.8 \\
\hline SPEEK & 53000 & 2.7 \\
\hline
\end{tabular}



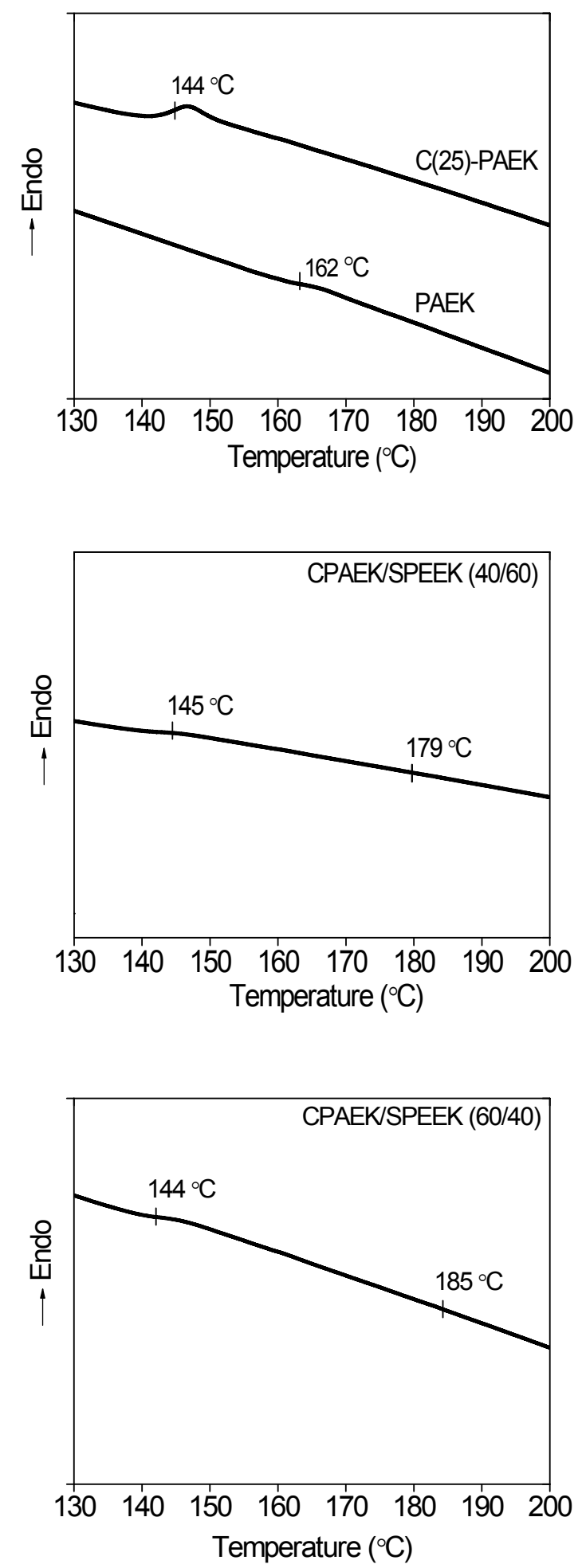

Fig S1. DSC graphs of CPAEK, PAEK polymers and CPAEK/SPEEK (40/60), CPAEK/SPEEK (60/40) blend membranes. 